\title{
Bioterrorism Preparedness: The Smallpox Vaccine Debate
}

\author{
Salah S. Qutaishat, PhD, Infection Control Department, Saint Joseph's Hospital, Marshfield, Wisconsin \\ John L. Olson, MD, Department of Internal Medicine, Marshfield Clinic, Marshfield, Wisconsin
}

[See related article 87 - 92]

\section{REPRINT REQUESTS:}

Salah S. Qutaishat, PhD

Saint Joseph's Hospital

611 Saint Joseph Avenue

Marshfield, WI 54449

Telephone: 715-387-9779

Fax: 715-387-7086

Email: qutaishs@stjosephs-marshfield.org

KEYWORDS:

Smallpox; Vaccine; Vaccinia;

Adverse events
On December 13, 2002 President Bush announced the White House plan to vaccinate approximately 500,000 military and civilian Americans against smallpox. ${ }^{1}$ The objective of the plan is to protect the people of the United States from the threat of smallpox as a potential bioterrorism agent employed by hostile groups or governments. On the civilian side, the plan is to form volunteer Smallpox Response Teams who are able to provide care to those affected in the event of a smallpox outbreak. These teams are composed of health care workers and others who may provide care to patients exposed to smallpox. At the present time, the plan does not recommend vaccination for the general public.

In this issue of Clinical Medicine \& Research, Belongia and Naleway ${ }^{2}$ present an argument that supports a limited smallpox vaccination program. This is based not only on the calculated risk of a smallpox bioterrorism attack as presented recently by Bozzette et al., ${ }^{3}$ but also the potential risk of vaccine-related events. These risks do not only apply to those who receive the vaccine but also those close contacts of vaccinated individuals.

The vaccination plan should be based on the benefits of the vaccine and the assessment of risks associated with it. Several experts are not in agreement with the White House plan. ${ }^{4}$ The disagreement is based on previous, well-documented experience with the best methods to prevent the transmission of smallpox. In contrast to a large-scale population vaccination program, it has been shown that a program such as "ring" vaccination can be more effective. 5

The vaccine benefit is not clearly identified based on our knowledge of a disease that does not exist, whereas, in a post-event setting there is clear reason to accept the risks. As documented by Belongia and Naleway, adverse events associated with smallpox vaccination are very uncommon and range from generalized vaccinia, to death. Other adverse events include eczema vaccinatum, encephalitis and progressive vaccinia. There are also adverse events including death due to secondary transmission of vaccinia, transmission associated with close contact to persons who recently received the vaccine. Published reports document twenty-six cases of secondary transmission within families. Three cases of the secondary transmission were fatal $(11.5 \%)$. Eighty-five, secondary cases of nosocomial vaccinia are reported in the literature, with nine associated deaths $(10.6 \%){ }^{6}$ 
The following adverse events were reported following the recent vaccination of more than 100,000 military personnel: encephalitis $(n=2)$, myocarditis $(n=1)$, generalized vaccinia

$(n=2)$ and ocular vaccinia $(n=1) .{ }^{7}$ To date, nine moderate-tosevere adverse events were reported following the recent vaccination of 19,919 civilian and public health care workers. These include; generalized vaccinia $(n=1)$, angina $(n=2)$, headache and dizziness $(n=1)$, cholecystitis $(n=1)$, hypertension $(n=1)$, vomiting and diarrhea $(n=1)$, exacerbation of COPD and diarrhea $(n=1)$, myocarditis $(n=1) \cdot 8,9,10$ Five cases of transmission to close contacts of military vaccinees were reported, two of these cases were diagnosed as ocular vaccinia. This low incidence of adverse events may be attributed to the pre-vaccination screening method that was used in order to scrutinize those selected to receive the vaccine and identify those at risk of developing adverse events.

The role of hospitals and physicians in bioterrorism preparedness is paramount. This readiness should not be limited to ensuring the safety and health of those who receive the smallpox vaccine and their contacts, but should include plans to handle actual bioterrorism events including a smallpox attack. Health care providers, including physicians, should develop a thorough understanding of bioterrorism agent characteristics, diagnostic and treatment options. Ultimately, this may be the best method to prevent and limit the impact of these events, either actual or hoax. Hospitals must enhance diagnostic capabilities and epidemiologic surveillance programs. Emergency preparedness programs must be modified to include bioterrorism. Above all, we must all educate ourselves. We must also not forget that an enhanced public health infrastructure will serve this nation well for the control of the disease, no matter the origin.

\section{REFERENCES}

1. Protecting Americans: Smallpox Vaccination Program. White House Web site. Available at: http://www.whitehouse.gov/ news/releases/2002/12/20021213-1.html (12/13/2002). Accessed March 11, 2003.

2. Belongia EA, and Naleway Al. Smallpox Vaccine: The Good, the Bad, and the Ugly. Clin Med Res 2003;1:87-92

3. Bozzette SA, Boer R, Bhatnagar V, Brower JL, Keeler EB, Morton SC, Stoto MA. A model for a smallpox-vaccination policy. N Engl J Med 2003;348:416-425.

4. Parker L. Hospitals balk at smallpox vaccine. USA Today. January 21, 2003.

5. Radetsky M. Smallpox: a history of its rise and fall. Pediatr Infect Dis J 1999;18:85-93.

6. Sepkowitz KA. How contagious is vaccinia? N Engl J Med 2003;348:439-446.

7. Smallpox Safety Summary, DoD Smallpox Vaccination Program. Military Vaccines Web site. Available at: http://www.smallpox.army.mil/media/pages/SPSafetySum.asp. Accessed March 11, 2003.

8. Smallpox Vaccine Adverse Events Among Civilians-United States, February 18-24, 2003. MMWR 2003;52(08);156157.

9. Smallpox Vaccine Adverse Events Among Civilians-United States, February 25-March 3, 2003. MMWR 2003;52(09); 180-181,191.

10. Smallpox Vaccine Adverse Events Among Civilians-United States, March 4-10, 2003. MMWR 2003;52(10);201-204. 